\title{
The relationship among psychological factors, neglect-like symptoms and postoperative pain after total knee arthroplasty
}

\author{
Yoshiyuki Hirakawa RPT MS ${ }^{1,2}$, Michiya Hara MD², Akira Fujiwara MD PhD², \\ Hirofumi Hanada MD PhD², Shu Morioka RPT PhD ${ }^{1}$
}

\begin{abstract}
Y Hirakawa, M Hara, A Fujiwara, H Hanada, S Morioka. The relationship among psychological factors, neglect-like symptoms and postoperative pain after total knee arthroplasty. Pain Res Manag 2014;19(5):251-256.
\end{abstract}

BACKGROUND: Persistent postoperative pain has a significant relationship with patient health and satisfaction.

OBJECTIVES: To investigate the prevalence and association of neglectlike symptoms (NLS) and other psychological factors on postoperative pain in patients following total knee arthroplasty (TKA). NLS are defined as the loss of perception of the limb with pain and excessive effort required to move the limb. The authors hypothesized that NLS were an important contributor to postoperative pain.

METHODS: The factors influencing pain were investigated using a longitudinal study with assessments at three and six weeks postsurgery. The relationships among demographic factors (age, body weight, body mass index), psychological factors (State-Trait Anxiety Inventory and Pain Catastrophizing Scale [PCS]) and NLS with postoperative pain were investigated in 90 patients after TKA. The associations among motor functions (muscle strength of knee extension, range of motion), sensory functions (joint position sense and two-point discrimination in the thigh) and NLS were also investigated.

RESULTS: At three and six weeks after surgery, 36\% and 19\% of patients, respectively, experienced NLS. In hierarchical multiple regression analysis, NLS and PCS scores were significantly associated with postoperative pain, while joint position sense and range of motion were significantly associated with NLS.

CONCLUSIONS: These results suggest that facilitation of sensory integration is important in rehabilitation after TKA because NLS appears to result from impaired sensory integration. The association of PCS scores with postoperative pain and NLS suggests the need to provide appropriate postoperative education to reduce persistent negative thoughts regarding future pain.

Key Words: Neglect-like symptoms; Pain catastrophizing; Postoperative pain; Postoperative rehabilitation; Total knee arthroplasty

$\mathrm{T}$ otal knee arthroplasty (TKA) is an effective surgical technique for alleviating severe knee pain associated with end-stage knee osteoarthritis, and the procedure generally improves quality of life (1). The level of patient satisfaction with their postoperative condition is $74 \%$ in Japan (2). However, persistence of postoperative pain can significantly influence satisfaction and quality of life $(3,4)$. The severity and prognosis of postoperative pain is associated with demographic factors, such as age, sex and body weight, and psychological factors including anxiety, depression, pain catastrophizing and mental health (5-8).

We hypothesized that neglect-like symptoms (NLS) would be associated with postoperative pain. Galer et al (9) and Galer and Jensen (10) defined NLS as loss of perception of the limb, with pain and

\section{Le lien entre les facteurs psychologiques, les symptômes évocateurs de négligence et la douleur postopératoire après une arthroplastie totale du genou}

HISTORIQUE : La douleur postopératoire persistante a un lien significatif avec la santé et la satisfaction du patient.

OBJECTIFS : Examiner la prévalence et l'association des symptômes évocateurs de négligence (SÉN) et d'autres facteurs psychologiques avec la douleur postopératoire des patients après une arthroplastie totale du genou (ATG). Les SÉN sont définis par la perte de perception du membre douloureux et l'effort excessif nécessaire pour le bouger. Les auteurs postulent que les SÉN contribuent largement à la douleur postopératoire.

MÉTHODOLOGIE : Les chercheurs ont examiné les facteurs influant sur la douleur au moyen d'une étude longitudinale comprenant des évaluations trois et six semaines après l'opération. Ils ont évalué les liens entre la douleur postopératoire et les facteurs démographiques (âge, poids, indice de masse corporelle), les facteurs psychologiques (questionnaire sur l'anxiété chronique et réactionnelle et échelle PCS de catastrophisation de la douleur) et les SÉN chez 90 patients après une ATG. Ils ont également évalué les associations entre les fonctions motrices (force musculaire de l'extension du genou, amplitude de mouvement), les fonctions sensorielles (sens de la position articulaire et discrimination en deux points de la cuisse) et les SÉN. RÉSULTATS : Trois et six semaines après l'opération, $36 \%$ et $19 \%$ des patients, respectivement, ressentaient des SÉN. Selon l'analyse de régression multiple hiérarchique, les SÉN et les indices de l'échelle PCS s'associaient de manière significative à la douleur postopératoire, tandis que le sens de la position de l'articulation et l'amplitude de mouvement s'associaient de manière significative aux SÉN.

CONCLUSIONS : D'après ces résultats, il est important de favoriser l'intégration sensorielle pendant la réadaptation qui suit une ATG, car les SÉN semblent découler d'une atteinte de l'intégration sensorielle. L'association des indices de l'échelle PCS avec la douleur postopératoire et les SÉN laisse supposer qu'il est nécessaire de fournir de l'information postopératoire pertinente afin de réduire les pensées négatives persistantes à l'égard de la future douleur.

excessive effort required to move the limb. The cause of NLS is believed to involve a deficiency in somatic sensory input and impaired ability to integrate this input (11); therefore, we also investigated the possible association of motor and sensory function on pain. Studies investigating NLS have included patients with complex regional pain syndrome (CRPS) (12,13); however, no postoperative survey investigating NLS in orthopedic patients has been conducted. Furthermore, the relationship between NLS and postoperative pain has not been in investigated in detail.

The objective of the present study was to investigate the prevalence and association of NLS and psychological factors on patients' postoperative pain.

\footnotetext{
${ }^{1}$ Graduate School of Health Sciences, Kio University, Nara; ${ }^{2}$ Department of Orthopedic Surgery, Fukuoka Rehabilitation Hospital, Fukuoka, Japan Correspondence: Mr Yoshiyuki Hirakawa, Graduate School of Health Science, Kio University, 4-2-2 Umami-naka, Koryo-cho, Kitakaturagi-gun, Nara 635-0832, Japan. Telephone 81-745-54-1601, fax 81-745-54-1600, e-mail yutsuki0903@yahoo.co.jp
} 
TABLE 1

Neglect-like symptoms questionnaire*

Item 1 If I don't focus my attention on my painful limb it would lie still, like dead weight

Item 2 My painful limb feels as though it is not part of the rest of my body

Item 3 I need to focus all of my attention on my painful limb to make it move the way I want it to

Item 4 My painful limb sometimes moves involuntarily, without my control Item 5 My painful limb feels dead to me

${ }^{*}$ Responses to each question were rated on a visual analogue scale 10 to 500). Items 1 and 3 assess motor neglect; items 2 and 5 assess cognitive neglect

\section{Study design and participants}

Factors influencing pain at three and six weeks postoperatively (PO3W and PO6W, respectively) were investigated using a longitudinal study design. PO3W and PO6W were chosen for the evaluations because activity levels have increased and postoperative pain may have persisted at these times.

The study participants were patients diagnosed with knee osteoarthritis who underwent initial TKA between June 2011 and November 2012 at Fukuoka Rehabilitation Hospital (Fukuoka, Japan). All participants were Japanese. Exclusion criteria were an inability to understand the objectives of the study due to dementia; mental health disorders; postoperative complications such as nerve injury and deep vein thrombosis; other significant medical diseases interfering with postoperative rehabilitation; previous TKA (TKA of the opposite limb and revision); and TKA performed for causes other than degenerative diseases (rheumatoid arthritis and bone necrosis). Ninety patients (20 men and 70 women) were selected according to these criteria. The same artificial joint model (posterior stabilized type) was used in all patients. All participants underwent general anesthesia, took oral analgesics (three tablets per day) until two weeks postsurgery and were assigned the same physiotherapy protocol following surgery.

\section{Factors potentially related to postoperative pain}

Demographic factors: Age, body weight and body mass index (BMI) were obtained from electronic medical records at Fukuoka Rehabilitation Hospital.

Pain: Postoperative pain was evaluated using a visual analogue scale (VAS). The participants repeated active movement maximum flexion and extension, and were asked to define the most severe pain by marking a point on a $100 \mathrm{~mm}$ line, with the left end indicating no pain and the right end indicating the most painful state. The examiner measured the distance $(\mathrm{mm})$ between the left end point and the participant's mark after the assessment.

Psychological factors: The psychological factors of anxiety and catastrophizing were assessed using the State-Trait Anxiety Inventory (STAI) and the Pain Catastrophizing Scale (PCS), respectively.

The STAI includes 20 questions rated on a four-point Likert scale ( 1 to 4 ), resulting in a total score between 20 and 80 . The STAI has been widely used to assess anxiety associated with pain after TKA and other surgeries $(14,15)$. The Japanese edition of the STAI (STAI-JYZ) has been used for similar assessments. A high internal consistency of the STAI-JYZ has been reported (Cronbach's $\alpha$ : 0.86 in men, 0.92 in women). The STAI-JYZ assesses state anxiety (STAI-1; the patient's current state of anxiety) and trait anxiety (STAI-2; the patient's usual level of anxiety). In the present study, only STAI-1 was used in the analyses.

Catastrophizing was assessed using the Japanese edition of the PCS (16). Catastrophizing is defined as a state in which excessive negative attention is devoted to pain stimulation and experience (17). The PCS consists of 13 questions in three categories (rumination [rumin], helplessness [helpless], and magnification [magni]) and has high internal consistency (Cronbach's $\alpha$ : PCS $=0.87$, rumin $=0.86$, helpless $=$ 0.66 and magni $=0.87)(18)$. The 13 questions are scored from 0 to 4 on a Likert scale, giving a total score ranging from 0 to 52 . The PCS predicts pain after surgery $(19,20)$ and has a strong association with postoperative TKA pain (20-23).

NLS was assessed using the questionnaire developed by Frettlöh et al (12) (Table 1), for which respondents use a VAS scale to indicate responses (using the same approach as that used for pain assessment). The distance $(\mathrm{mm})$ from the left end of the $100 \mathrm{~mm}$ line was defined as the VAS NLS score (NLS score) for each of the five items of the scale, resulting in a total NLS score ranging from 0 to 500 . Consistent with Galer and Jensen (10), items 1 and 3 measured motor neglect $(\mathrm{MN})$, a state requiring particular attention to move the affected limb, and items two and five measured cognitive neglect $(\mathrm{CN})$, representing reduced ability to perceive the presence of the affected limb. MN and $\mathrm{CN}$ were viewed as subcategories of NLS.

\section{Factors related to postoperative NLS}

To investigate factors related to NLS, motor function (muscle strength and range of motion $[\mathrm{ROM}]$ ) and sensory function (joint position sense [JPS] and two-point distance [TPD]) were assessed at PO3W and PO6W. All measurements were obtained by one physical therapist.

Motor function: The motor function factors evaluated were ROM and muscle strength of the knee.

For muscle strength measurement, the participants sat on a table and the maximum isometric muscle strength $(\mathrm{kg})$ of the knee extensor was measured at $60^{\circ}$ flexion of the knee joint using a micro total analysis system ( $\mu$ TAS F-1; Anima Corporation, Japan). The measurement pad of the $\mu$ TAS F-1 was attached to the distal tibia and fixed to a leg of the table with a band. Measurements were performed for the nonoperative knee followed by the operative knee in triplicate, with a rest period of $30 \mathrm{~s}$ between measurements. The mean muscle strength was calculated and standardized according to body weight.

To determine ROM, the maximum range of flexion of the knee joint was measured during active movement. Patients were assessed while supine on a bed using the ROM measurement method specified by the Japanese Orthopaedic Association and Japanese Association of Rehabilitation Medicine (1995). The femoral axis was the baseline axis, a line connecting the fibular head and lateral malleolus was the axis of movement, and the angle formed by the baseline axis and axis of movement on the dorsal side was measured using a goniometer (SG150, Biometrics Ltd). The angle was recorded to the nearest degree.

Sensory function: Sensory function was evaluated using the JPS of the knee and the TPD of the thigh.

For the JPS measurement, the participants sat on a table with their feet not touching the floor in a relaxed state. Each participant closed his or her eyes, and the examiner held the participant's heel from below and extended the knee to a specific position. The examiner held this position for $5 \mathrm{~s}$, and the participant memorized the angle of knee flexion during this period (the specified angle). The knee was returned to the original position after $5 \mathrm{~s}$. The knee was then passively reextended by the examiner, and the knee joint flexion angle was measured when the participant believed that the angle had reached the memorized position (the reproduced angle). The absolute difference between the specified and reproduced angles was determined using a Dualer IQTM digital inclinometer (JTech, USA). Measurements were performed in triplicate for the nonoperative knee followed by the operative knee, and the mean was used for analysis.

The TPD was measured at the centre of the thigh in a supine position using Moberg's method. Using a plastic caliper, two prongs were pressed against the thigh until the skin colour changed to white. The distance between the prongs was initially $3 \mathrm{~cm}$ and was increased in $1 \mathrm{~mm}$ increments. The subject responded 'one' or 'two' when feeling one or two points, respectively, and the minimum distance between the prongs perceived as two points was measured. The measurement interval was $7 \mathrm{~s}$ (24). The subjects were instructed not to guess. Measurements were performed in triplicate, and the mean was used for analysis.

\section{Ethical considerations}

The objectives, methods and predicted results were explained to participants, using documents in accordance with the Declaration of 
Helsinki. Written consent was obtained from all patients. The present study was approved by the Ethics Committee of Fukuoka Rehabilitation Hospital (approval number 2012-6-1).

\section{Statistical analyses}

The Kolmogorov-Smirnov test was used to confirm the normality of all variables. At PO3W and PO6W, single regression analysis of postoperative pain was performed for the variables, and variables with $\mathrm{P}<0.10$ were included in the subsequent multiple regression analysis (25). To resolve multicollinearity, correlation coefficients between all variables were calculated using Pearson correlation analysis. For two variables with $r>0.80$, only the variable with the strongest association with postoperative pain in the simple regression analysis was included in the multiple regression analysis.

In the multiple regression analysis, the dependent variable was the VAS measure of postoperative pain and the independent variables were those potentially related to postoperative pain: patient demographic characteristics, psychological factors and NLS scores. Demographic characteristics (age, body weight, BMI) were entered first as control variables, followed by psychological factors in the second step (the scores of the STAI-1 and PCS categories of rumin, helpless and magni), and the NLS MN and CM scores in the third step.

Measures of postoperative NLS were evaluated as independent variables using multiple regression analysis, with NLS as the dependent variable. Motor function and sensory function were hierarchically included in the analysis. All statistical analyses were performed using SPSS version 18.0 (IBM Corporation, USA).

\section{RESULTS}

\section{Patient characteristics}

Means and SDs for age, sex, body weight, BMI and classification of the operative limb are shown for all participants in Table 2. Age, sex ratio and BMI were similar to the means reported for Japanese and Asian individuals in previous studies $(3,25)$. The mean, SD, kurtosis, skewness, and maximum and minimum values of each variable are presented in Table 3. The mean $( \pm$ SD) VAS scores for pain were $37.5 \pm 19.9$ and $26.7 \pm 20.9$ at PO3W and PO6W, respectively, showing a tendency for pain to decrease over time. Motor function reflected by knee extensor strength, and ROM and sensory function reflected by the JPS and TPD measures improved from PO3W to PO6W.

The NLS total, NLS MN, and NLS CN scores were higher at PO3W and decreased at PO6W. Cronbach's $\alpha$ was $\geq 0.92$ for the NLS MN, NLS CN and NLS total scores at both assessment time points, showing high internal consistency. However, the SD was high, indicating a large variation among patients. The percentage of patients with a total NLS $\geq 100$ was $36 \%(\mathrm{MN}, 40 \% ; \mathrm{CN}, 18 \%)$ at PO3W and $19 \%(\mathrm{MN}, 19 \% ; \mathrm{CN}, 5 \%)$ at PO6W. The mean scores for NLS items 1 and 3 (MN subset) were high at both assessment time points; Frettlöh et al (12) also found a high score on item 3 score in patients with CRPS or chronic pain. Thus, MN appears to be the main symptom of postoperative NLS. The $\mathrm{CN}$ score was higher at $\mathrm{PO} 3 \mathrm{~W}$ than at PO6W, which suggested that $\mathrm{CN}$ appeared soon after surgery and gradually decreased thereafter.

The psychological factors measured by the STAI and PCS also decreased from $\mathrm{PO} 3 \mathrm{~W}$ to $\mathrm{PO} 6 \mathrm{~W}(\mathrm{P}<0.01$, paired $t$ test). The mean PCS score was 13.0 and 9.3 at PO3W and PO6W, respectively, representing a gradual decrease over time after surgery. These values are relatively low compared with other studies; for example, Riddle et al (26) used a PCS cutoff value of 16 . Cronbach's $\alpha$ was $\geq 0.92$ for the STAI, PCS and subitems, revealing high internal consistency.

\section{Factors related to pain at PO3W and PO6W}

The factors related to pain at PO3W are shown in Table 4. Singleregression analysis was performed with $\mathrm{PO} 3 \mathrm{~W}$ pain as a dependent variable and other factors as independent variables. The BMI, NLS total, NLS MN, PCS total and PCS rumin scores were strongly associated $(\beta>0.50)$. Factors with $\mathrm{P}>0.10$ or a correlation coefficient of

\section{TABLE 2}

Sample characteristics $(n=90)$

\begin{tabular}{ll}
\hline Characteristic & \\
\hline Age, years & $76.0 \pm 6.3$ \\
Body weight, $\mathrm{kg}$ & $58.4 \pm 11.4$ \\
Body mass index, $\mathrm{kg} / \mathrm{m}^{2}$ & $26.1 \pm 4.0$ \\
Sex, $\mathrm{n}$ & \\
$\quad$ Male & 20 \\
Female & 70 \\
Laterality, $\mathrm{n}$ & \\
Right & 42 \\
Left & 48 \\
\hline
\end{tabular}

Data presented as mean $\pm S D$ unless otherwise indicated

$r>0.70$ with another factor were excluded, leaving the scores of the STAI-1, PCS rumin, PCS helpless, PCS magni, NLS MN and NLS $\mathrm{CN}$ for inclusion in hierarchical multiple regression analysis, with PO3W as the dependent variable. The scores of the STAI-1, PCS rumin, PCS helpless, and PCS magni were included in step 1, and the NLS MN and NLS CN scores were included in step 2. This analysis produced values of $\mathrm{R}^{2}=0.33, \mathrm{~F}=10.07 \quad(\mathrm{P}<0.01)$ after step 1 and $\mathrm{R}^{2}=0.56, \mathrm{~F}=34.63(\mathrm{P}<0.01)$ after step 2 , showing improvements of 0.23 and 24.56, respectively. The PCS rumin and NLS MN scores were significantly associated with PO3W (Table 4).

The variables associated with postoperative pain at $\mathrm{PO} 6 \mathrm{~W}$ are shown in Table 5. Single-regression analysis with PO6W as the dependent variable showed strong associations with the STAI-1, PCS rumin, NLS total and NLS MN scores at $\beta>0.50$. Factors with $P>0.10$ or $r>0.70$ were excluded, and hierarchical multiple regression analysis was performed using the same factors and steps as for PO3W. The resultant values were $\mathrm{R}^{2}=0.45, \mathrm{~F}=16.61(\mathrm{P}<0.01)$ after step 1 and $\mathrm{R}^{2}=0.62, \mathrm{~F}=33.33 \quad(\mathrm{P}<0.01)$ after step 2 , with improvements of 0.17 and 16.72 , respectively. The PCS rumin and NLS MN score emerged as factors significantly associated with PO6W (Table 5).

Factors related to postoperative NLS at PO3W and PO6W

The variables associated with the NLS score at PO3W and PO6W are shown in Tables 6 and 7, respectively. Because a significant association with pain was found for the NLS MN score at PO3W and PO6W, the NLS MN score was the dependent variable. Single-regression analysis of the NLS MN score at PO3W was strongly associated with muscle strength, ROM and JPS at $\beta>0.50$. After exclusion of factors with $\mathrm{P}<0.10$ and $\mathrm{r}>0.70$, hierarchical multiple-regression analysis was performed; the muscle strength and ROM measures were entered in step 1 and the JPS measure was entered in step 2. The results of the analysis were $\mathrm{R}^{2}=0.10, \mathrm{~F}=4.16(\mathrm{P}<0.01)$ after step 1 and $\mathrm{R}^{2}=0.15, \mathrm{~F}=4.54$ $(\mathrm{P}<0.01)$ after step 2 , with improvements of 0.05 and 0.38 , respectively. The JPS measure was significantly associated with the NLS MN score at PO3W (Table 6).

A similar approach was taken for the NLS MN score at PO6W, which had a strong association with the muscle strength, ROM and JPS measures at $\beta>0.50$ in single regression analysis. After exclusion of factors with $\mathrm{P}>0.10$ or $\mathrm{r}>0.70$, hierarchical multiple regression analysis was performed using the same factors and steps as those for the NLS MN score at $\mathrm{PO} 3 \mathrm{~W}$. The results were $\mathrm{R}^{2}=0.15, \mathrm{~F}=7.37(\mathrm{P}<0.01)$ after step 1 and $\mathrm{R}^{2}=0.30, \mathrm{~F}=11.70(\mathrm{P}<0.01)$ after step 2, indicating improvements of 0.15 and 4.33 , respectively. The ROM and JPS measures were significantly associated with the NLS MN score at PO6W (Table 7).

\section{DISCUSSION}

NLS has been reported to occur in patients with CRPS and chronic pain. In the present study, it was observed in patients after TKA. Galer and Jensen (10) reported a NLS rate of $84 \%$ in CRPS patients, Förderreuther et al (27) observed NLS in $54.4 \%$ of 114 CRPS patients with impaired fingers, and Frettlöh et al (12) observed NLS in $90.2 \%$ 
TABLE 3

Descriptive statistics for all variables

\begin{tabular}{|c|c|c|c|c|c|c|}
\hline Factor & Variables & Mean \pm SD & Kurtosis & Skewness & Range & Chronbach o \\
\hline Pain & Three weeks postsurgery & $37.5 \pm 19.9$ & -0.78 & 0.12 & $0-80$ & \\
\hline & Motor neglect subscale & $62.1 \pm 61.9$ & -0.75 & 0.61 & $0-220$ & \\
\hline \multirow[t]{2}{*}{ Motor function } & Strength of knee extension & $0.16 \pm 0.01$ & 1.72 & 0.99 & $0.03-0.40$ & \\
\hline & Range of motion & $107.9 \pm 17.2$ & 2.31 & -1.31 & $45-135$ & \\
\hline Sensory function & Joint position sense & $6.8 \pm 2.8$ & 2.27 & 1.13 & $2-18$ & \\
\hline \multirow{4}{*}{$\begin{array}{l}\text { Psychological } \\
\text { factors }\end{array}$} & PCS Total & $13 \pm 9.3$ & 2.01 & 1.38 & $0-44$ & 0.96 \\
\hline & PCS Rumination subscale & $8.5 \pm 5.1$ & -0.33 & 0.46 & $0-20$ & 0.99 \\
\hline & PCS Helplessness subscale & $2.2 \pm 3.7$ & 5.58 & 2.36 & $0-17$ & 0.98 \\
\hline & PCS Magnification subscale & $2.3 \pm 2.5$ & 1.06 & 1.16 & $0-10$ & 0.92 \\
\hline \multirow[t]{2}{*}{ Motor function } & Strength of knee estension & $0.2 \pm 0.07$ & 4.33 & 1.54 & $0.09-0.51$ & \\
\hline & Range of motion & $113.9 \pm 15.6$ & 2.09 & -1.25 & $60-145$ & \\
\hline \multirow[t]{2}{*}{ Sensory function } & Joint position sense & $5.4 \pm 1.9$ & 0.24 & 0.69 & $2-10.3$ & \\
\hline & Two-point distance & $44.7 \pm 6.8$ & 2.24 & 1.06 & $32-72$ & \\
\hline \multirow{5}{*}{$\begin{array}{l}\text { Psychological } \\
\text { factors }\end{array}$} & State-Trait Anxiety Inventory-1 & $26.6 \pm 9.2$ & 5.27 & 2.09 & $20-65$ & 0.94 \\
\hline & PCS Total & $9.3 \pm 9.4$ & 2.51 & 1.45 & $0-47$ & 0.94 \\
\hline & PCS Rumination subscale & $6.2 \pm 5.7$ & -0.85 & 0.61 & $0-20$ & 0.95 \\
\hline & PCS Helplessness subscale & $1.3 \pm 2.9$ & 10.4 & 3.01 & $0-16$ & 0.96 \\
\hline & PCS Magnification subscale & $1.9 \pm 2.2$ & 3.25 & 1.55 & $0-11$ & 0.92 \\
\hline
\end{tabular}

${ }^{* *} P<0.01 ;{ }^{*} P<0.05$. NLS Neglect-like symptoms; PCS Pain Catastrophizing Scale

\section{TABLE 4}

Hierarchical multiple regression analysis at three weeks postsurgery $(n=90)$

\begin{tabular}{lccccc}
\hline Dependent variable: Postoperative week 3 & & & \\
\hline & $\boldsymbol{\beta}^{*}$ & $\mathbf{R}^{\mathbf{2}}$ & $\mathbf{S R}^{\mathbf{2}}$ & $\mathbf{F}$ & $\boldsymbol{\Delta} \mathbf{F}$ \\
\hline Step 1 & & 0.33 & & $10.07^{\dagger}$ & \\
STAl-1 & -0.02 & & & & \\
PCS Rumination subscale & $0.24^{\dagger}$ & & & & \\
PCS Helplessness subscale & 0.09 & & & & \\
PCS Magnification subscale & 0.05 & & & & \\
Step 2 & & 0.56 & 0.23 & $34.63^{\dagger}$ & 24.56 \\
NLS Motor neglect subscale & $0.50^{\dagger}$ & & & & \\
NLS Cognitive neglect subscale & 0.15 & & & & \\
\hline
\end{tabular}

${ }^{*} \beta$ weights are from the final regression equation; ${ }^{\dagger} P<0.01$. NLS Neglect-like symptoms; PCS Pain Catastrophizing Scale; STAl-1 State-Trait Anxiety Inventory-1

of CRPS patients and $80.3 \%$ of patients with chronic pain. Compared with these studies, the prevalence of NLS in the current study was comparatively low (36\% and $18 \%$ at PO3W and PO6W, respectively). Postoperative $\mathrm{MN}$ was strongly associated with pain after TKA. In turn, motor function (ROM) and sensory function (JPS) of the TKAtreated knee joint were associated with postoperative MN.

Reduction of sensory function with acute (27) or chronic paininduced reduction of motor function is common $(23,28-32)$ and may occur due to narrowing of the pain-related sensorimotor cortex caused by plastic changes $(33,34)$. Lewis et al $(11)$ suggested that reduced perception of the affected limb, as in NLS, is caused by body perception disturbance associated with pain-induced remapping of the central nervous system, while Vartiainen et al $(33,35)$ reported reduced
TABLE 5

Hierarchical multiple regression analysis at six weeks postsurgery $(n=90)$

\begin{tabular}{lcllll}
\hline Dependent variable: Postoperative week $\mathbf{6}$ & & & & \\
\hline \multicolumn{1}{l}{$\boldsymbol{\beta}^{*}$} & $\mathbf{R}^{\mathbf{2}}$ & $\mathbf{\Delta R}^{\mathbf{2}}$ & $\mathbf{F}$ & $\boldsymbol{\Delta} \mathbf{F}$ \\
\hline Step 1 & & 0.45 & & $16.61^{\dagger}$ & \\
STAI-1 & 0.13 & & & & \\
PCS Rumination subscale & $0.27^{\dagger}$ & & & & \\
PCS Helplessness subscale & -0.11 & & & & \\
PCS Magnification subscale & 0.02 & & & & \\
Step 2 & & 0.62 & 0.17 & $33.33^{\dagger}$ & 16.72 \\
NLS Motor neglect subscale & $0.53^{\dagger}$ & & & & \\
NLS Cognitive neglect subscale & -0.03 & & & & \\
\hline
\end{tabular}

${ }^{*} \beta$ weights are from the final regression equation; ${ }^{\dagger} P<0.01$. NLS Neglect-like symptoms; PCS Pain Catastrophizing Scale; STAl-1 State-trait Anxiety Inventory-1

activity of the posterior parietal cortex (PPC) in CRPS patients and proposed that this hypofunction of the PPC may be a cause of NLS. Sensations of equilibrium input by the somatic, visual, auditory and vestibular sensory systems are integrated in the PPC and form the body image. Thus, NLS is impaired sensory integration and a subjective assessment of sensory-motor conflict. Sensory-motor conflict can exacerbate pain (36). The results of the present study suggest that a decrease of limb perception after surgery generated NLS and the possible exacerbation of postoperative pain.

In our study, JPS was identified as an aspect of sensory function associated with MN at PO3W; ROM and JPS were found to be associated with MN at PO6W. Reduced JPS may be a key element of postoperative MN because JPS and MN were associated at both time 
TABLE 6

\section{Hierarchical multiple regression analysis at postoperative} week $3(n=90)$

\begin{tabular}{lccccc}
\hline $\begin{array}{l}\text { Dependent variable: Neglect-like symptoms motor neglect score at } \\
\text { postoperative week 3 }\end{array}$ & $\boldsymbol{\beta}^{*}$ & $\mathbf{R}^{2}$ & $\mathbf{\Delta \mathbf { R } ^ { 2 }}$ & $\mathbf{F}$ & $\mathbf{\Delta F}$ \\
\hline & & 0.10 & & $4.16^{\ddagger}$ & \\
\hline Step 1 & -0.14 & & & & \\
$\quad$ Strength & -0.16 & & & & \\
$\quad$ Range of motion & & 0.15 & 0.05 & $4.54^{\ddagger}$ & 0.38 \\
Step 2 & \\
$\quad$ Joint position sense & $0.23^{\dagger}$ & & & & \\
\hline
\end{tabular}

${ }^{*} \beta$ weights are from the final regression equation; ${ }^{\dagger} P<0.05 ;{ }^{\ddagger} P<0.01$. Strength Strength of knee extension

points. Accurate feedback of motor sensation cannot be obtained due to reduction of this somatosensory function, producing errors between the intended movement and sensory feedback due to movement, which may lead to a reduction of motor functions and cognitive representations of the limb. Galer et al (9) defined MN as a condition requiring excess mental and visual attention to movement of one's own limb, indicating a reduced sense of agency (37). van den Bos et al (38) suggested that a sense of agency is produced through matching predicted movement with the resulting sensory feedback, and this sense of agency is strengthened by consistency between somatosensory and visual information. In our study, $\mathrm{MN}$ was related to pain at $\mathrm{PO} 3 \mathrm{~W}$ and PO6W, suggesting the importance of treatment for MN accompanied by an impaired sense of agency for postoperative rehabilitation after TKA. It may be necessary to recover a sense of agency in the early phase of postoperative recovery by paying attention to somatic sensation, sense of joint position and matching intended movement with sensory feedback information.

Approximately $18 \%$ of our patients experienced NLS CN postoperatively, and it was aggravated transiently at PO3W. CN is defined as a feeling that the affected limb does not belong to the patient (9), representing a state of reduced sense of body ownership of the affected limb. The sense of body ownership is formed by sensory integration of visual and somatic sensations $(39,40)$, which suggests that not only are motor functions, such as muscle strength and ROM, disturbed, but senses of agency and body ownership are also reduced at PO3W after TKA. Reduced somatosensory information causes errors in sensory feedback between somatic sensation and other sensory modalities such as visual and tactile sensations. McCabe et al (36) stated that this discrepancy in sensory feedback causes pain, and Harris et al (40) proposed that inconsistency between the intention and result of movement induced by plastic changes in the sensorimotor cortex causes pain. Sumitani et al (41) reported that a prism adaptation task that matches visual and somatosensory information reduced chronic pain in CRPS patients in whom perception of the middle of their own body had deviated toward the affected side, suggesting that prolonged impairment of postoperative senses of body ownership and agency may lead to chronic postoperative pain. Thus, postoperative rehabilitation that integrates sensory modalities while avoiding pain induction is important.

PCS rumin and NLS MN scores were the factors that were significantly associated with pain at PO3W and PO6W. Catastrophic thinking about pain represents a negative or persistent psychological state (21) that may influence the severity of postoperative pain (26). Kendell et al (42) found that this mental state was involved in the short-term outcome of rehabilitation after TKA. In our study, rumination, a subitem of the PCS that refers to persistent thinking about pain (42) and an indication of anxiety about future pain, was associated with pain and the NLS score at PO3W and PO6W. Forsythe et al (22) found that marked rumination on the PCS before surgery served as a predictor of pain at 12 and 24 months postsurgery. Van Damme et al (43) found that a task to direct attention away from pain in the presence of fear and catastrophic thinking about pain may aggravate pain, while Sullivan et al $(19,44)$ suggested that education on how to avoid excess attention to pain and anxiety was required for patients with
TABLE 7

Hierarchical multiple regression analysis at postoperative week $6(n=90)$

\begin{tabular}{|c|c|c|c|c|c|}
\hline $\begin{array}{l}\text { Dependent variable: } \\
\text { postoperative week } 6\end{array}$ & lect-like & mpton & hotor $r$ & lect sco & \\
\hline & $\beta$ & $\mathbf{R}^{2}$ & $\Delta \mathrm{R}^{2}$ & $\mathbf{F}$ & $\Delta \mathrm{F}$ \\
\hline Step 1 & & 0.15 & & $7.37^{* *}$ & \\
\hline Strength & -0.13 & & & & \\
\hline Range of motion & $-0.28^{* *}$ & & & & \\
\hline Step 2 & & 0.30 & 0.15 & $11.70^{* *}$ & 4.33 \\
\hline Joint position sense & $0.39^{* *}$ & & & & \\
\hline
\end{tabular}

${ }^{*} P<0.05 ;{ }^{* *} P<0.01$. Strength Strength of knee extension

higher levels of rumination. Identifying the presence and foundation for anxiety after TKA and offering appropriate explanations of the progress and prognosis may be important to address this issue.

\section{Limitations}

A limitation of the present study was that all subjects were Japanese, older and had lower BMIs than those in previous studies, which mainly involved Caucasians. However, the results do not differ markedly from those of studies involving Asians, including Japanese patients $(3,45)$. The present study examined the factors related to postoperative pain for up to six weeks after surgery. There is a need to investigate the impact on long-term prognosis, such as after a year or more.

\section{CONCLUSIONS}

Our results show that postoperative NLS and catastrophic thinking about pain were associated with pain levels after TKA, and that JPS and catastrophic thinking about pain were associated with NLS. Impaired body perception function due to a deficiency of somatic sensation and impaired integration of sensory modalities, such as visual and somatic sensations, are believed to be causes of NLS. Therefore, recovery of somatosensory function through sensory input, such as JPS, and promoting integration with other sensory modalities while avoiding pain may be important in rehabilitation after TKA. An educational approach for anxiety in patients with catastrophic thinking about pain may be necessary to address the psychological state in which excess attention is devoted to pain and the patient has a negative belief about the prognosis regarding pain.

DISCLOSURES: The authors have no conflicts of interest to declare.

FUNDING: None.

\section{REFERENCES}

1. Bonnin MP, Basiglini L, Archbold HA. What are the factors of residual pain after uncomplicated TKA? Knee Surg Sports Traumatol Arthrosc 2011;19:1411-7.

2. Hosaka K, Saito S, Ishii T, Mori S, Sumino T, Tokuhaski Y. Asian-specific total knee system: 5-14 year follow-up study. BMC Musculoskelet Disord 2011;12:251.

3. Matsuda S, Kawahara S, Okazaki K, Tashiro Y, Iwamoto Y. Postoperative alignment and ROM affect patient satisfaction after TKA. Clin Orthop Relat Res 2013;471:127-33.

4. Dickstein R, Heffes Y, Shabtai EI, Markowitz E. Total knee arthroplasty in the elderly: Patients' self-appraisal 6 and 12 months postoperatively. Gerontology 1998;44:204-10.

5. Elson DW, Brenkel IJ. Predicting pain after total knee arthroplasty. J Arthroplasty 2006;21:1047-53.

6. Singh JA, Lewallen DG. Predictors of use of pain medications for persistent knee pain after primary total knee arthroplasty:

A cohort study using an institutional joint registry. Arthritis Res Ther 2012;14:R248.

7. Desmeules F, Dionne CE, Belzile E, Bourbonnais R, Frémont P. Waiting for total knee replacement surgery: Factors associated with pain, stiffness, function and quality of life. BMC Musculoskelet Disord 2009;10:52. 
8. Vissers MM, Bussmann JB, Verhaar JA, Busschbach JJ, Bierma-Zeinstra SM, Reijman M. Psychological factors affecting the outcome of total hip and knee arthroplasty: A systematic review. Semin Arthritis Rheum 2012;41:576-88.

9. Galer BS, Butler S, Jensen MP. Case reports and hypothesis: A neglect-like syndrome may be responsible for the motor disturbance in reflex sympathetic dystrophy (Complex Regional Pain Syndrome-1). J Pain Symptom Manage 1995;10:385-91.

10. Galer BS, Jensen M. Neglect-like symptoms in complex regional pain syndrome: Results of a self-administered survey. J Pain Symptom Manage 1999;18:213-7.

11. Lewis JS, Kersten P, McCabe CS, McPherson KM, Blake DR. Body perception disturbance: A contribution to pain in complex regional pain syndrome (CRPS). Pain 2007;133:111-9.

12. Frettlöh J, Hüppe M, Maier C. Severity and specificity of neglectlike symptoms in patients with complex regional pain syndrome (CRPS) compared to chronic limb pain of other origins. Pain 2006;124:184-9.

13. Kolb L, Lang C, Seifert F, Maihöfner C. Cognitive correlates of "neglect-like syndrome" in patients with complex regional pain syndrome. Pain 2012;153:1063-73.

14. Boeke S, Duivenvoorden HJ, Verhage F, Zwaveling A. Prediction of postoperative pain and duration of hospitalization using two anxiety measures. Pain 1991;45:293-7.

15. Brander VA, Stulberg SD, Adams AD, et al. Predicting total knee replacement pain: A prospective, observational study. Clin Orthop Relat Res 2003;416:27-36.

16. Matsuoka H, Sakano Y. Assessment of cognitive aspect of pain: Development, reliability, and validation of Japanese version of Pain Catastrophizing Scale. Jpn J Psychosom Med 2007;47:95-102. (Article in Japanese).

17. Sullivan MJL, Bishop SR, Pivik J. The Pain Catastrophizing Scale: Development and validation. Psychol Assess 1995;7:524-32.

18. Sullivan MJ, Thorn B, Haythornthwaite JA, et al. Theoretical perspectives on the relation between catastrophizing and pain. Clin J Pain 2001;17:52-64.

19. Sullivan MJ, Tanzer M, Reardon G, Amirault D, Dunbar M, Stanish W. The role of presurgical expectancies in predicting pain and function one year following total knee arthroplasty. Pain 2011;152:2287-93.

20. Lautenbacher S, Huber C, Baum C, Rossaint R, Hochreins S, Heessen M. Attentional avoidance of negative experiences as predictor of postoperative pain ratings and consumption of analgesics: Comparison with other psychological predictors. Pain Med 2011;12:645-53.

21. Papaioannou M, Skapinakis P, Damigos D, Mavreas V, Broumas G, Palgmesi A. The role of catastrophizing in the prediction of postoperative pain. Pain Med 2009;10:1452-9.

22. Forsythe ME, Dunbar MJ, Hennigar AW, Sullivan MJ, Gross M. Prospective relation between catastrophizing and residual pain following knee arthroplasty: Two-year follow-up. Pain Res Manag 2008;13:335-41.

23. Roth ML, Tripp DA, Harrison MH, Sullivan M, Carson P. Demographic and psychosocial predictors of acute perioperative pain for total knee arthroplasty. Pain Res Manag 2007;12:185-94.

24. Moseley GL, Zalucki NM, Wiech K. Tactile discrimination, but not tactile stimulation alone, reduces chronic limb pain. Pain 2008;137:600-8.

25. Rakel BA, Blodgett NP, Bridget Zimmerman M, et al. Predictors of postoperative movement and resting pain following total knee replacement. Pain 2012;153:2192-203.
26. Riddle DL, Wade JB, Jiranek WA, Kong X. Preoperative pain catastrophizing predicts pain outcome after knee arthroplasty. Clin Orthop Relat Res 2010;468:798-806.

27. Förderreuther S, Sailer U, Straube A. Impaired self-perception of the hand in complex regional pain syndrome (CRPS). Pain 2004;110:756-61.

28. Sörös P, Knecht S, Bantel C, et al. Functional reorganization of the human primary somatosensory cortex after acute pain demonstrated by magnetoencephalography. Neurosci Lett 2001;298:195-8.

29. Juottonen K, Gockel M, Silén T, Hurri H, Hari R, Forss N. Altered central sensorimotor processing in patients with complex regional pain syndrome. Pain 2002;98:315-23.

30. Luomajoki H, Moseley GL. Tactile acuity and lumbopelvic motor control in patients with back pain and healthy controls. Br J Sports Med 2011;45:437-40.

31. Maihöfner C, DeCol R. Decreased perceptual learning ability in complex regional pain syndrome. Eur J Pain 2007;11:903-9.

32. Maihöfner C, Neundörfer B, Birklein F, Handwerker HO. Mislocalization of tactile stimulation in patients with complex regional pain syndrome. J Neurol 2006;253:772-9.

33. Vartiainen N, Kirveskari E, Kallio-Laine K, Kalso E, Forss N. Cortical reorganization in primary somatosensory cortex in patients with unilateral chronic pain. J Pain 2009;10:854-9.

34. Flor $\mathrm{H}$. The modification of cortical reorganization and chronic pain by sensory feedback. Appl Psychophysiol Biofeedback 2002;27:215-27.

35. Vartiainen NV, Kirveskari E, Forss N. Central processing of tactile and nociceptive stimuli in complex regional pain syndrome. Clin Neurophysiol 2008;119:2380-8.

36. McCabe CS, Haigh RC, Halligan PW, Blake DR. Simulating sensory-motor incongruence in healthy volunteers: Implications for a cortical model of pain. Rheumatology (Oxford) 2005;44:509-16.

37. Bultitude JH, Rafal RD. Derangement of body representation in complex regional pain syndrome: Report of a case treated with mirror and prisms. Exp Brain Res 2010;204:409-18.

38. van den Bos E, Jeannerod M. Sense of body and sense of action both contribute to self-recognition. Cognition 2002;85:177-87.

39. Botvinick M, Cohen J. Rubber hands 'feel' touch that eyes see. Nature 1998;391:756.

40. Harris AJ. Cortical origin of pathological pain. Lancet 1999;354:1464-6.

41. Sumitani M, Rossetti Y, Shibata M, et al. Prism adaptation to optical deviation alleviates pathologic pain. Neurology 2007;68:128-33.

42. Kendell K, Saxby B, Farrow M, Naisby C. Psychological factors associated with short-term recovery from total knee replacement. Br J Health Psychol 2001;6:41-52.

43. Van Damme S, Crombez G, Van Nieuwenborgh-De Wever K, Goubert L. Is distraction less effective when pain is threatening? An experimental investigation with the cold pressor task. Eur J Pain 2008;12:60-7.

44. Sullivan MJ, Stanish W, Waite H, Sullivan MJ, Tripp DA. Catastrophizing pain and disability in patients with soft-tissue injuries. Pain 1998;77:253-60.

45. Bin Abd Razak HR, Chong HC, Tan AH. Obesity does not imply poor outcomes in Asians after total knee arthroplasty. Clin Orthop Relat Res 2013;471:1957-63. 


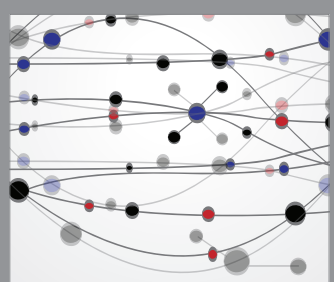

The Scientific World Journal
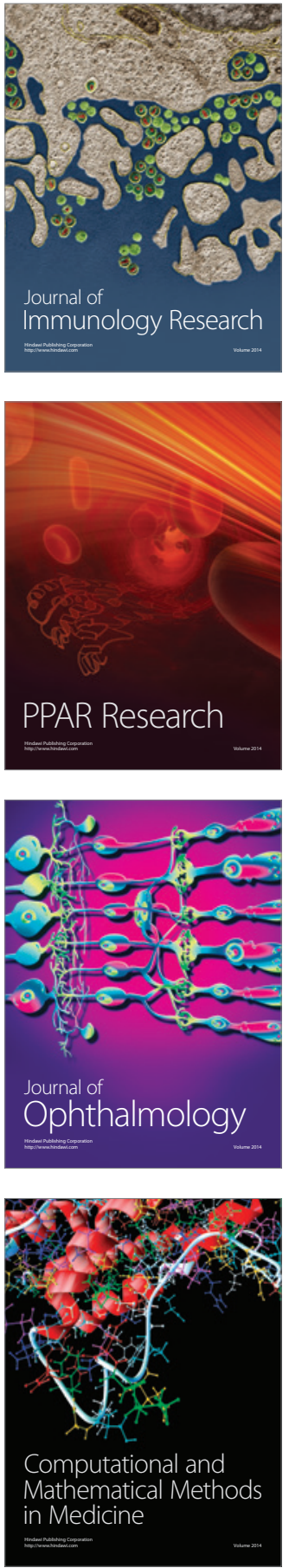

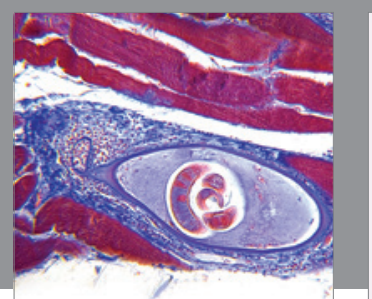

Gastroenterology Research and Practice

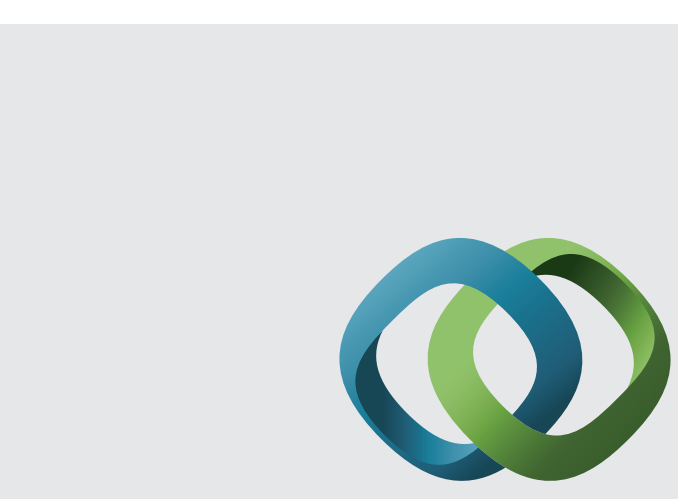

\section{Hindawi}

Submit your manuscripts at

http://www.hindawi.com
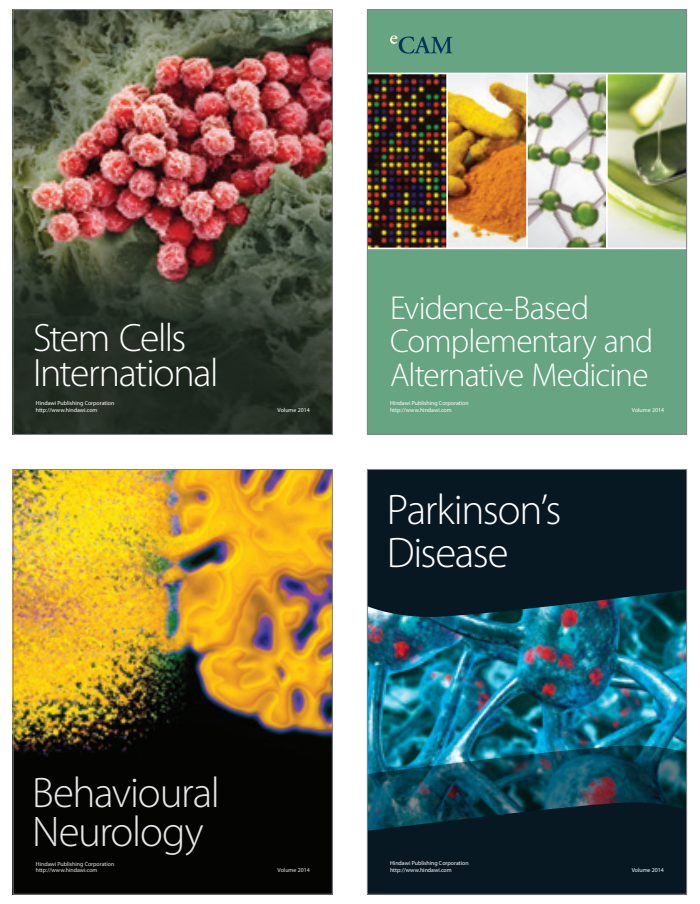
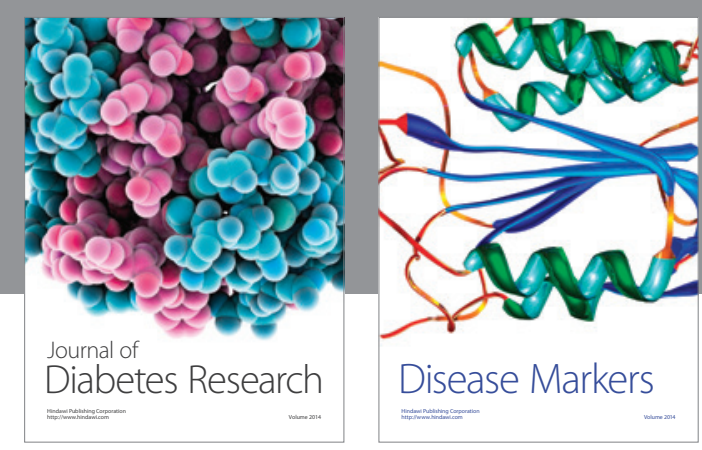

Disease Markers
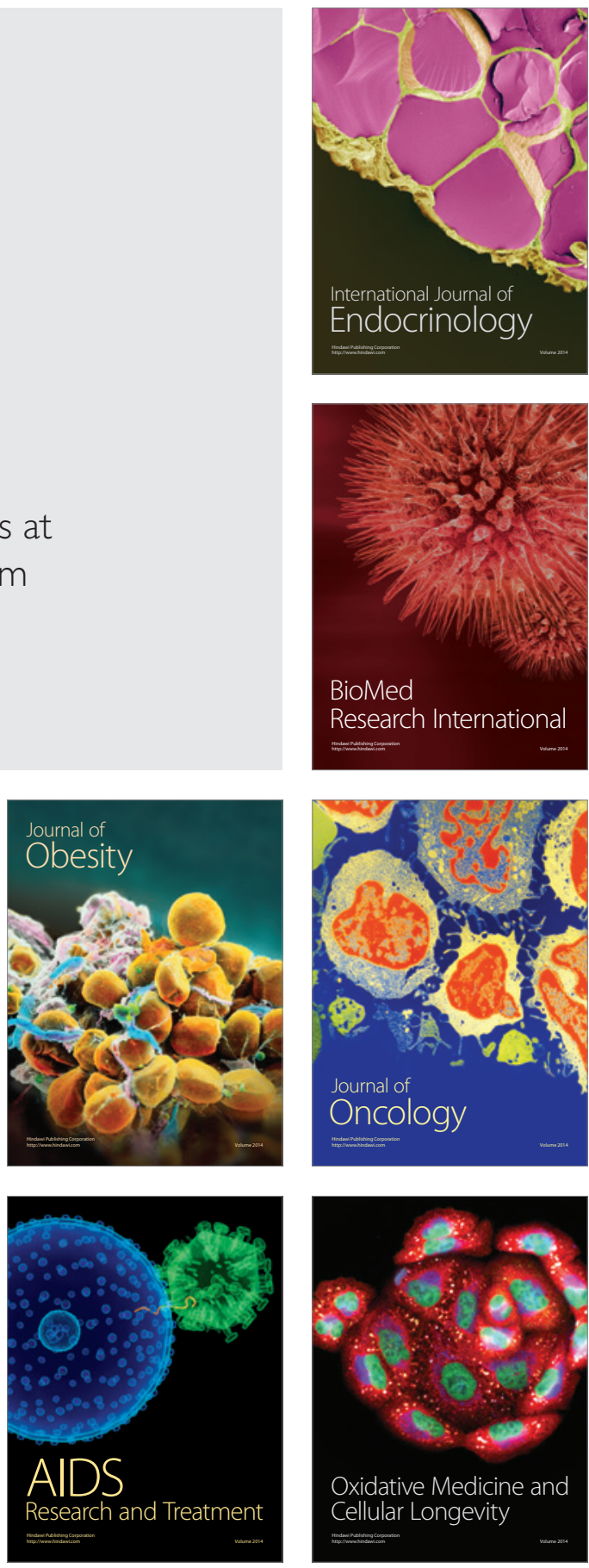